\title{
Practical Wisdom and Big Data Dilemmas: The Case of the Swedish Transport Administration
}

\author{
Lena Hylving \\ Halmstad University, \\ School of Information Technology \\ Lena.hylving@hh.se
}

\author{
Susanne Lindberg \\ Halmstad University, \\ School of Information Technology \\ Susanne.lindberg@hh.se
}

\begin{abstract}
Using big data in organizations has the potential to improve innovation, accuracy, and efficiency. Big data is also connected with risks for both the organization and society at large. It is therefore important to improve our understanding of potential consequences of implementing and using big data. We studied the Swedish Transport Administration to understand their attitude towards implementing big data for prediction of, for example, the need for road maintenance. The analysis identified four moral dilemmas that the organization deals with in connection to big data. We discuss these dilemmas from the perspective of practical wisdom. Practical wisdom is manifested in contextdependent actions connected to open-mindedness, reflection and judgment. It can be summed up as "the reasonable thing to do" in a unique situation where "not-knowing" is a helpful resource when making wise decisions. This paper seeks to shed light on the importance of practical wisdom when implementing big data.
\end{abstract}

\section{Introduction}

Practical wisdom has received limited attention in the IS community [1]. Moreover, it has been highlighted how practical wisdom is being overpowered by other types of knowledge that are considered more fact-based [2], [3]. Digital data is often considered as hard facts [4], and the collection and manipulation of lots of digital data is often called Big Data (hereafter referred to as BD).

$\mathrm{BD}$ can be described using the five V's - Volume, Velocity, Veracity, Value and Variety [5]. With the five V's you can, for example, predict pandemics [6], community activity [7] and traffic [8], to name a few. Thus, the possibilities of BD are endless, yet there are certain limitations. Although you can be precise and at the same time see certain patterns with the help of $\mathrm{BD}$, there are nuances that might get lost [2], [9].

The prevailing discourse on BD tends to focus on algorithms and possibilities for developing the use of BD [10]. Less research is focused on understanding the complexities that arise from implementing $\mathrm{BD}$ analyses for prediction in organizations; in this, social science and qualitative approaches play a key role [11]. Most studies on ethics and consequences of $\mathrm{BD}$ are furthermore performed by researchers within computer science, or similar fields, which has contributed to the lack of diversity within the discourse [12]. It is important to study the possible consequences of BD and understand that the conception of these analyses is subjective; a level of interpretation is always needed. As such, Kappler et al. [11] call for more social science in the study of the societal implications of BD as we have seen consequences that do not always benefit individuals or society at large [2], [9].

With this as a background, we therefore focus on practical wisdom and BD in this study. Practical wisdom can be described as "the reasonable thing to do" in relation to the particulars of the specific situation [13][14] and is an integrated and multi-dimensional practice in which reflection, moral value-based judgement, and open-mindedness work in parallel to reach a common good for the many. It concerns the indefinable gut feeling that, although it might seem inadequate and incompetent to follow, research shows often takes you in a good direction [15].

Following Aristotle's definition, practical wisdom, or phronesis as he called it, means that a person acts for the common good based on his or her cognitiveemotional abilities. It is about taking action without knowing all the facts but instead using self-other awareness along with multi-perspective considerations, such as moral codes. [16][13]. In fact, not-knowing goes hand in hand with practical wisdom and is "a central condition to attain wisdom in practice" [17, p. 49].

As a first step towards ensuring wise use of BD, we have studied the Swedish Transport Administration (hereafter referred to as STA) in their efforts to implement and use BD. Our aim in this paper is to improve understanding of an organization's attitude towards implementing BD for prediction and at the same time make an effort to highlight the usefulness, importance and applicability of practical wisdom [18].

\section{Related Literature}




\subsection{Practical Wisdom}

Aristotle's definition of practical wisdom can be described as referring to the quality possessed by someone who applies her wisdom in a particular situation, is open-minded and always strives for the common good by getting in touch with her "felt emotions and moral sensibilities" [1, p.377], traits often repressed in today's society. Being open-minded creates opportunities for creativity and new ways of understanding and interpreting situations [19], [20], supports curiosity and exploration, and uses the horizon of not-knowing [17]. Not-knowing helps us attain practical wisdom because it lets us perceive and respond non-intellectually to situations from a deep and foundational level of a unique experience. It enables us to use a more refined perception of particulars so that we can respond more wisely. Just like being practical wise, not-knowing is a way of being, a quality of awareness, and a mode of perception [17]. They go hand in hand since they both emerge in unique situations where openmindedness and judgment are central.

Applying practical wisdom is related to intuition and is an integrated cogni-emotional reflective process where intra-, inter-, and extra-personal interests are balanced in order to reach a common good for as many as possible [16]. In a decision-making process, intuition, or gut feeling, is used based on the "right feeling". However, it is difficult to articulate the exact reason and details behind the decision since this "feeling" engages cognitive processes that are not always articulative [16]. Although it might seem inadequate and incompetent to follow one's gut feeling, research has shown that it often takes you in a good direction [15]. Furthermore, research indicates that people with a lot of experience are more likely to follow their gut feeling than to employ complex analysis and analytics [21].

The description of practical wisdom comprises "mental states" and moral virtues, which cannot be reduced to a single measure [22], and the dynamics involved are intertwined and emerge in action. Moreover, the attainment of practical wisdom relies on experiences, and since each experience is unique, quantity matters. That is, opportunities for numerous experiences support the development of practical wisdom.

Accordingly, it is an experience-based knowledge that, when in use, balances the most appropriate options to achieve a "good" outcome with an ethical foundation. In this continuous and dynamic process, essential and unique details are identified and used to balance the act of judging the best path forward when dealing with moral dilemmas, but are also used to learn new things, add to the repertoire of experiences, and expand the knowledge horizon [20]. Performing practical wisdom includes the art of using these details and moral virtues in order to make a wise, practical decision.

Limited research within the IS community has focused on practical wisdom [1]. Hence, in an effort to produce a world that we seek to describe and explain [18], and to infuse this world with more practical wisdom, we use practical wisdom as a lens in this study to better understand $\mathrm{BD}$ implementation and usage.

\subsection{Big Data and Its Possible Consequences}

BD analytics is, in essence, a combination of very large datasets and complex analytics, together making up one of the most significant current technological trends [28]. Artificial intelligence and BD are considered to have the potential to surpass human reasoning and the ability to make complex predictions [29]. BD is typically described using a number of V's, most commonly including (1) Volume, the quantity of data; (2) Velocity, the speed at which data is available and analysed in real-time; (3) Variety, the heterogeneity of the data, both in structure and source; (4) Veracity, how accurate the data is, with processes for avoiding the creation of "bad data"; and (5) Value, the end goal of using $\mathrm{BD}$ in order to create value for the organization [5], [30], [31]. BD is, simply put, used to discover unknown possibilities in existing datasets; thus, these datasets need to be considerable and detailed [28]. What makes $\mathrm{BD}$ unique is its unprecedentedly large quantities of data, that it is organic, and that it can have a global reach [32].

$\mathrm{BD}$ is seen as a determinant of the innovative capacity of an organization [30], [33] due to the improved prediction for supporting decision making [10]. While many researchers highlight possibilities for using $\mathrm{BD}$ analysis, others also emphasize challenges and possible consequences to organizations and society. An exaggerated view of the potential for using BD can according to some obscure the possibilities for understanding the possible consequences that relying on BD analyses can have [2], [9], [29]. However, challenges for responsible use of $\mathrm{BD}$ are often linked to privacy, data protection and integrity [12], [33]. Yet, in an organizational context, the challenges can be more complex and encompassing.

The question of value for the organization is vital to the motivation for implementing BD analyses into the processes of an organization [30], yet societal value and risk management are less frequently in focus in research [34]. On an individual level, BD is argued to lead to a society of control, with risks for discrimination and manipulation [2], [11]. On an organizational level, ethical questions include whether or not to centralize or decentralize the $\mathrm{BD}$ analysis, how to improve business models, and how to manage stakeholder interests such 
as privacy concerns [10]. There are currently no universal ethical guidelines for using $\mathrm{BD}$, and the guidelines that do exist tend to focus primarily on accountability, fairness and privacy, and almost wholly lack discussion on effect to practice [12].

To many organizations, privacy and ethical issues are seen as a customer issue and thus external from the organization [10]. On the other hand, organizations are quick to tap into the potential value of using BD [30], which has led to several cases in which the use of BD has had a negative impact on individuals or society [2], [9], [34]. While many organizations are increasingly raising ethical questions concerning $\mathrm{BD}$, these are still not considered to be essential to the organization itself [10]. That BD is still in the early stages of its potential also contributes to a lack of experience concerning consequences of extensive use of BD analysis.

There are very few ethical guidelines for BD use that relate to, for example, social responsibility, welfare, or ecological sustainability [12]. In a study of perceptions of ethics in BD, Greene et al. [34] conclude that while $\mathrm{BD}$ is considered to be the result of human agency, there is at the same time a deterministic view of consequences from the use of $\mathrm{BD}$ in society as something handled only by experts. This deterministic view leads to a sense that organizations, or even society at large, need to adapt to $\mathrm{BD}$ use, instead of taking control of the consequences it can cause. The complexity of BD contributes to this view [29].

Zwitter [32] identifies three different BD stakeholders: the BD collectors, who collect and store the data; the BD utilizers, who use the data, sometimes in ways other than what was intended by the collector; and the BD generators, who are the sources of the data. There is an uneven power relationship between these stakeholders, and this also contributes to the lack of feeling of control over how BD is used. While some argue that, for example, anonymization of data makes it safe to share [11], data cannot be entirely anonymous and still hold value, and because the BD utilizer may be different from the collector, there is no way to control how data is used [32]. It becomes clear that implementing BD in organizations is complex, but also that it can have severe consequences if not handled wisely.

\section{Methodology}

Engaged scholarship is an approach to studying complex situations and wicked problems (i.e. problems that have contradicting requirements, are ill defined, and trying to solve them can cause irreversible consequences [35]). This method was chosen as it is a practical and participatory approach to complex research while allowing for a contribution that can benefit both theory and practice [36].

\subsection{Research Setting}

This study was conducted at the Swedish Transport Administration (STA), which is accountable for longterm planning and operations of the national transport system in Sweden. The STA is responsible for the overall physical and digital infrastructures connected to transportation and mobility in Sweden. This has in recent years been transformational since digitalization has exploded in the area of transport and mobility with, for example, the development of autonomous and electronic vehicles and sensor technology. This has caused many new opportunities as well as challenges. One of the areas the organization is currently focusing on is $\mathrm{BD}$, which they refer to as "the new gold". In their description of future research and development areas for 2019-2024, the STA states the following in regard to BD:

"Data about our behaviour is the new gold. In a data-driven society, artificial intelligence, combined with big data, is used to create value both within the organization as well as to the customer. New technology, solutions and tools will shape the organizations and individuals of tomorrow and no one can say with exact certainty how digital we want, or can, be."

The usage and application of $\mathrm{BD}$ are growing both within and outside the STA and, as the quote above shows, the STA wants to make the most out of BD and its possibilities. Consequently, a great deal of focus is on what they can do with the BD in order to improve their services for society, organizations and individuals.

\subsection{Data Collection}

This study mainly relied on 11 semi-structured interviews that were carried out over Skype and Zoom during spring 2020. Each interview lasted for approximately one hour and they were all audiorecorded. The selection of interviewees was based on two criteria: (1) involvement in different BD projects currently running on STA, and (2) possibility to influence and make decisions about future implementation and usage of BD. The interviewees had the following roles within the organization: investigation leader of digitalization of the transport system, service owner, advisor and project manager for ITS, department manager, senior advisor IT, program manager of digitalization of the transport system, data protection representative, manager for road conditions, digitalization strategist, and two interviewees working as enterprise architects. 
Questions used in the interviews were explorative and open-ended. The questions focused mainly on ethics and value-based rationality such as "How do you discuss ethics in relation to BD implementation?" and "What do you think are important values in relation to $\mathrm{BD}$ and AI?" We also asked questions that concerned usage of $\mathrm{BD}$ at STA and what challenges and possibilities they had noticed.

Two other approaches to data collection were used to triangulate findings in order to avoid biases from a single data source [38]. In addition to the interviews, we studied documents produced and used by the organization and conducted a workshop with employees at the STA. The documents used in the analysis included different descriptions of, for example, how data collection from traffic roads was carried out and the STA's vision and mission. This assisted in developing a better understanding of context, development work and company strategy.

Finally, we conducted a workshop with 17 people from different units at the STA to discuss a range of topics related to BD, including ethics, sustainability, and Aristotle's concept of phronesis. The dilemmas identified during the interviews were discussed and more dilemmas could be identified after analysing the discussion from the workshop. Some of the workshop participants were the same people we interviewed. The workshop was audio-recorded, and extensive notes were taken throughout the workshop and typed up soon afterwards to ensure accuracy.

\subsection{Data Analysis}

The analysis was performed using a thematic analysis approach as this is a flexible and suitable method for identifying patterns in empirical material of different kinds [39]. From the interviews, documents and workshop that make up the empirical material for this study, a number of patterns, in this case seen as moral dilemmas, emerged through the thematic analysis. The analysis followed the steps of thematic analysis described in [39].

The analysis started with the transcription of the interviews, followed by in-vivo coding. In-vivo coding was considered suitable for this study as it allows for the words of the interviewees to guide the analysis, thus remaining close to the empirical material [40]. The analysis was iterative where, for example, some interviewees talked about ethical concerns regarding integrity in relation to the anonymized data they collected. This made us return to the literature and understand what sensitizing devices in terms of concepts and theories could help us further [41]. The initial coding resulted in 80 codes ranging from holistic perspectives of, for example, how the agency influenced society at large, to individual issues, such as personal ownership of collected data.

While iteratively coding, the codes were categorized into themes. Codes were structured into themes based on their potential relevance to the research question. When iteratively analysing the empirical data and reading relevant research [42], our attention was drawn more and more to the complex relationship between BD and practical wisdom, which we decided to focus on in more detail. The analysis resulted in the identification of four themes, which were identified to represent moral dilemmas that the organization had to handle in order to implement BD analyses wisely. In this context, moral dilemmas were defined as a conflict between two actions that present different moral values, and where the actions are mutually exclusive [43].

By using relevant literature concerning both BD (i.e. [10], [34]) and practical wisdom (i.e. [21], [44], [30]), we improved our understanding of the organization's attitude towards using BD for prediction.

\section{Research Outcome}

This section presents the four identified dilemmas.

\subsection{The Value of Gut Feeling vs "Objective" Big Data}

During the interviews, it was articulated that intuition or gut feeling was an integral part of the STA's operations and it was highlighted as something that is valued highly by both management and employees. BD was especially used as a foundation for prediction and decision making. As the organization is currently focusing on BD, concerns about the value of gut feeling have been raised, questioning the reliability of gut feelings compared to BD analyses. However, there are also worries about BD since "it is mostly loose parts of information that we are using to build decision-support systems".

The goal of using BD is to objectively systematize, be more accurate and efficient, and rely less on subjective individual employees. Many employees are in doubt and wonder how to deal with the relationship between gut feeling and $\mathrm{BD}$ analyses, that is, if they should trust numbers (aka objective data) over experience. A department manager describes the situation:

"If you've been working in a region for 20 years and you are very experienced, you have a kind of gut feeling for what the problem is and what measures have to be taken. You could say that this gut feeling is what we want to systematize. That we shouldn't have to rely on these people who have worked here for 20 years, but that we 
should instead know this by collecting a lot of information."

The move towards using BD analyses for prediction also means that tasks, or possibly whole positions, may be eliminated or adjusted to fit the new BD-driven organization. One example raised was the prediction of ice and snow on the roads. Traditionally, it has been up to the employees working with winter road maintenance to predict when they need to clear the roads and to know what roads are the most dangerous when it is snowing, and thus need to be cleared first. Their experience and gut feeling helped in deciding when it was time to start the maintenance. Using BD analyses of, for example, weather forecasts, car sensor information and accident statistics, the STA can now predict and plan in advance where, when and how to clear snow. This leads to safer roads but also a need for fewer employees to clear the roads as well as more difficulties in finding a "correct level" of maintenance, as the objective data can be specific about where, when and how. With more data usage for better prediction, it is difficult to find the "correct level" of maintenance because it is a balance of costs and outcome. The manager for road conditions said:

"This [how to handle BD] is a tough nut to crack because you need some sort of practical wisdom when you put in the [data] values. [...] And we also need practical experience or an understanding, or knowledge I would say. Because we can set unreasonable requirements that raise the cost and that have consequences for both environment and costs."

The STA tries to hold on to and appreciate gut feeling even though BD analyses are expanding and they are increasingly making use of BD. Contrarily, it was mentioned that the organization should dare to take more data-driven, objective decisions instead of following a gut feeling. This emphasizes the need for adjusting how gut feelings and BD are valued in the organization. The organizational culture values gut feeling and long experience highly, yet there are many advantages to relying on $\mathrm{BD}$ analyses, for both accuracy and efficiency as well as safety. The moral dilemma for the organization thus becomes determining how much emphasis should be placed on gut feeling versus BD, and when to use which, how much and why.

\subsection{Integrity vs Openness}

The STA does not come in contact with individual customers but has well-established relationships with both public and private companies that supply the transport system in Sweden and abroad. Because of this tradition, they argue that they don't have to deal with integrity issues because they don't deal with individuals. The consensus is that anonymization makes data safe to share, and that the beneficial value of BD outweighs the minor risks of possible ethical concerns. The senior advisor IT said:

"We're not interested in humans, really, but in the streams that allow people to move in the transportation system."

Meanwhile, the organization works with, for example, car manufacturers that collect data from individual vehicles. This data is used to analyse information such as road wear, traffic patterns, and accident statistics. The STA also collaborates with various GPS system providers, who want data for improving their services. Consequently, the STA has a lot of information on companies and also provides information to many companies. Yet there is currently no discourse within the organization on the potential consequences of sharing data on vehicles with external partners, as called out by a data protection representative:

"It's not really a question that is brought up that often [about BD and integrity] and that is because we don't actually keep track of individuals but vehicles."

Still, examples exist from when publishing data had unexpected consequences that the STA had not calculated. One was reported on a Swedish television show called Uppdrag granskning [Mission Examination], where they identified 15,000 dangerously built road curves. Part of the report was based on data from the STA. While this use of the data was unexpected by the STA, the interviews emphasize that this openness leads to better safety and a higher level of trust towards the STA, as they do not attempt to hide mistakes. Nevertheless, it also shows that the STA cannot predict how their data will be analysed, and thus there is a need for safeguarding, for example, data that may lead to the identification of individuals.

Within the organization, the question of public access to information is valued highly. The Public Access to Information and Secrecy Act is fundamental to the Swedish government and also integral to the STA. As a result, the goal of the organization is to publish as much data as openly as possible. This was also articulated by the investigation leader of digitalization of the transport system:

"It is expected at both the EU and national levels that we should release as much data as possible openly, in order to promote innovation and ultimately create a better society."

However, the organization also values the nation's safety highly, and a massive effort goes into classifying data and anonymizing, for example, facilities critical to the nation's defence. The investigation leader continues:

"The major discussion [about the aggregation of data] is about security. We have facilities that have critical societal functions that we want to protect, and 
certain data that we have is classified quite strictly. /... We might perform lab tests to determine what information could be discovered if the facilities were anonymized, and test functionality."

These contradicting concerns within the organization highlight questions of integrity and the responsibility for what data is published. They argue that they do not handle data on individual humans, but on "dead matter", which has few consequences for society at large. A service owner describes what they have done at STA:

"We have worked a lot with anonymizing so that recordings can't be connected to individuals. I.../ As long as it concerns inanimate objects and we can be predictive, there isn't much ethical discussion necessary, in my opinion."

The moral dilemma for the organization thus becomes how to balance the ethical issue of safeguarding for individuals and stakeholders, while still maintaining an openness that is highly valued in the organization and for its stakeholders.

\subsection{Efficiency vs Core Values}

Using $\mathrm{BD}$ analyses for prediction and decision making creates many opportunities for the STA regarding efficiency, effectiveness and safety. They argue, for example, that it will be possible to gain advantages for ecological sustainability by more accurately predicting different traffic situations. The digitalization strategist said:

"I think that we should use digitalization as part of the solution to reduce carbon emissions."

Ecological sustainability is a crucial question at the STA, as it is part of the Swedish government's climate targets for 2030. However, increased efficiency will also allow for the building of a larger quantity of roads, which in turn will most likely lead to an increase in traffic and emissions. In the workshop, the advisor and project manager for ITS said:

"There is an ethical and moral issue to work with at the STA when it comes to creating a sustainable future. But we are also part of the solution. So, we are both the problem and the solution."

However, this view is not wholly shared, as the data protection representative expressed during the workshop:

"Many problems are external to us. Cars create emissions, but it's the automotive industry that electrifies the cars."

In this sense, there is a contradiction between the goal of using BD analyses within the STA and the overarching, long-term ecological sustainability goals. The contradicting views within the organization also appear to contribute to a lack of dialogue on the societal effects of the organization's principal occupation. This is not a contradiction that arises solely from the use of $\mathrm{BD}$ analyses within the organization, but it is increased in the many possible advantages to efficiency and accuracy gained from relying on BD.

As the STA plays a key role in urban development, their actions have a societal effect. They set the conditions for societal development, for example by determining where roads will be built or not built, and thus enabling the areas to be used for shopping malls or apartment complexes. The use of BD for simulations helps the STA understand some of the long-term consequences of their actions in ways that other types of analyses cannot. An enterprise architect said:

"[BD can be used to] simulate and so forth. To see the societal effects. It's like this, if we rebuild... for example, restaurants that have relied on a specific road passing somewhere disappear after we build a new road. We've seen that multiple times. There are discussions on this, of course..."

There is thus a contradiction in how the BD analysis can be used. On the one hand, it can be used to simulate traffic situations and reduce carbon emissions by making traffic flows more efficient. On the other hand, these simulations can also result in new roads that will lead to more traffic, which contradicts the STA's core value of sustainability. Both are heightened by the use of BD analyses and this causes a moral dilemma in terms of the efficiency of BD analyses versus the consequences of that efficiency. Balance, in this case, implies an understanding of multiple perspectives that might contradict what is of value.

\subsection{Sharing vs Not Sharing}

The use and sharing of BD pave the way for collaboration possibilities with a diverse set of actors. Being part of a broader context of organizations enables the sharing and collecting of data to create distinct value for its stakeholders. It also creates value internally for the STA. Being able to analyse data from subcontractors or supplement the STA's own data with that of other actors, enables quality improvements in the BD analyses. This can have consequences for many different goals the STA works for, such as traffic safety. The manager for road conditions explains:

"...taking GPS positioning from maintenance vehicles. That was a bit tricky at first, whether we could keep track of them, but when they had done this for a while it turned out that the maintenance subcontractors were able to better plan their logistics. So, they saw the advantages afterwards."

The complexity of knowing if it is worth using certain data, along with ethical issues like integrity, causes uncertainty. 
Similarly, external actors are interested in data from the STA, as this will allow them to provide value for their customers. As such, the organization has the possibility of a symbiosis with subcontractors and external actors, in which they provide value to each other. However, not knowing how data will be used, and what responsibility that requires, makes the organization hesitant even though the possibilities with the data can create a lot of value both for specific organizations as well as for the society at large.

The STA's current philosophy is that other actors have to adapt to their systems and processes whenever possible. The program manager for digitalization of the transport system expressed his concern:

".... we provide the data and then we normally say: adapt to our format. /... / We are the hub, we decide, we determine how this is supposed to look, and others have to adapt. That's our typical approach."

However, regarding "giants", such as Google, the STA has to adapt. The manager continues:

"The world doesn't really work like that, because these ecosystems, for example, Google and Waze, they expect that anyone who wants to be part of that ecosystem adapts to it. So, we took a step where we said $O K$, we will adapt our delivery of data - we added a way to collect the data that is what Waze needs."

Although the STA has traditionally been seen as a trustee of the physical transportation infrastructure in Sweden, today the organization has become rather more of an urban developer instead. This shift has caused a need for an increase in ethical discourse from a more holistic perspective. It also brings with it an opportunity to improve society. In this, the STA also has to collaborate with other actors, and sharing data can create opportunities not only for more accurate development but also for adding value to society.

"I try to see the STA as part of a larger ecosystem, and not as a sole actor. We have to act based on the fact that we have to work a lot with others. /.../ We try to trust that there are actually others that are better at some things than we are, and to use the power of these commercial actors instead of finding our own solutions in all situations."

Knowing what "the reasonable thing to do" is isn't always obvious, as it can be difficult when the outcomes and consequences of sharing and collecting data with many different types of actors are unknown. There are possibilities to create value from adapting to large, as well as smaller, actors, but knowing when this is worth it, and for whom it creates value, is tricky. The moral dilemma for the organization becomes determining how to understand when a situation warrants being open for adaptation to enable sharing and thus gain mutual value through collaboration, and when it is more suitable not to share $\mathrm{BD}$.

\section{Discussion}

From the empirical study, we have identified four moral dilemmas from a perspective of wise implementation of BD. These are summarized in Table 2 below.

Table 2 Summary of four identified moral dilemmas connected to practical wisdom and BD

\begin{tabular}{|c|c|}
\hline Dilemma & Description \\
\hline $\begin{array}{l}\text { The value of } \\
\text { gut feeling vs } \\
\text { "objective" } \\
\text { BD }\end{array}$ & $\begin{array}{l}\text { Gut feeling is valued within the } \\
\text { organization but is starting to be } \\
\text { suppressed by the implementation of } \\
\text { BD analyses. The dilemma for the } \\
\text { organization thus becomes how to } \\
\text { wisely balance how much emphasis } \\
\text { should be on gut feeling versus BD, } \\
\text { and when to use which, how much } \\
\text { and why. }\end{array}$ \\
\hline $\begin{array}{ll}\text { Integrity } & \text { vs } \\
\text { openness } & \end{array}$ & $\begin{array}{l}\text { The dilemma for the organization } \\
\text { how to balance openness vers } \\
\text { integrity (and other ethical issu } \\
\text { such as privacy). Although the ST } \\
\text { is anonymizing data, it can be us } \\
\text { for unpredicted causes without t } \\
\text { STA's knowledge and conser } \\
\text { Consequently, wise use of BD } \\
\text { relation to openness and ethic } \\
\text { issues is important and a diffic } \\
\text { dilemma to take on and discuss. }\end{array}$ \\
\hline
\end{tabular}

Efficiency vs $\quad$ BD can simultaneously enable and core values inhibit reaching set goals. Relying more on BD analyses can make the organization more effective and efficient in terms of planning and predicting, for example, traffic flow. Yet it can also lead to building more roads that increase the traffic, which goes against the organization's ecological sustainability objectives. Thus, discussions regarding how to prioritize between different goals should be guided by wise considerations and reflections.

Sharing vs Sharing data with, and collecting not sharing data from, external actors promises value-creation possibilities for both the organization and external actors. The dilemma of not knowing when to adjust and adapt and when to ask collaborators to adjust and adapt is complex and costly. Reasonable collaboration with large and small actors is difficult. Yet the data can be equally important and valuable. 


\begin{tabular}{|l|l|}
\hline & $\begin{array}{l}\text { Hence, using judgement and } \\
\text { practical wisdom is important so that } \\
\text { "the reasonable thing to do" is } \\
\text { chosen. }\end{array}$
\end{tabular}

The empirical study identified four dilemmas in which the STA was faced with multiple choices in their use and implementation of BD. The dilemmas do not present easy answers but summarize the attitudes and complexities concerning implementing $\mathrm{BD}$ in the studied organization. There were discrepancies in opinions concerning how to take on BD and a general awareness of these dilemmas has yet to be articulated. However, the workshop showed that an interest existed, together with an openness and eagerness to discuss and bring to light these issues. This discussion will focus on understanding the role of practical wisdom in these dilemmas.

The empirical study illustrates that gut feeling is highly valued in the organization. Practical wisdom is tightly connected to gut feeling, which in many cases leads to qualitative and correct decisions [15]. Consequently, gut feeling should not be suppressed, but rather encouraged in order to get a balance between gut feeling and implementation of $\mathrm{BD}$, as they both offer benefits. However, we see in the study that the STA is moving away from relying on gut feeling towards relying and being more dependent on BD analysis for planning and making decisions. This can result in decisions less beneficial for the common good, and also a loss of competence that might be important and relevant when $\mathrm{BD}$ is wrongly applied and implemented [2], [9], as practical wisdom is something that comes with experience and needs to be practiced constantly.

As concerns introducing BD into decisions and planning, gut feeling and practical wisdom have a role in guiding how that implementation should be carried out and later used. With this also comes taking control of, and being responsible for, ethical design in $\mathrm{BD}$ use [34]. In this work, practical wisdom is essential so that the implementation of BD enables the organization to be continuously wise and appreciate the benefits of not always "knowing" everything but rather embracing the "not-knowing" and following a gut feeling [17], [45]. By doing this, the organization will continue to learn and be dynamic [17], [46].

The research outcome harmonizes with other research showing that there is great potential in using BD in organizations [28], especially in connection with sharing data openly. Many can benefit from the usage of open data. This resonates with the typical view of $\mathrm{BD}$ as a determinant for how innovative an organization can be [30], [33]. However, although the organization is aware of risks such as privacy and integrity, the STA does not have an ongoing dialogue regarding what the moral thing to do is, or consequences regarding ethics and BD. Because ethics vary over time, while data is more or less static (once collected, the individual data entity is static), it is important to have continuous discussions focusing on the openness of data and ethics. Being open-minded is a part of acting wisely [22]. Therefore, continuous discussion concerning open data and its consequences also increases the ability to act wisely as well as to be creative and innovative [19] in a society of constant change.

This study shows that while BD has the potential to support a main goal of the organization (in this case, traffic safety and traffic flow), it also constitutes risks to other goals within the organization and for the common good (in this case, dilemmas relating to ecological sustainability versus making the transport system safe and efficient by improving the infrastructure with new roads). Dilemmas like this open up for complex discussions and prioritizations about how to make the most, and the best, out of the data. Taking the time for wise discussions based on reflection, open-mindedness, creativity and exploration can have innovative outcomes [19] and assist organizations in solving moral dilemmas in the best possible way. However, if ethical dilemmas like these are neglected, tensions can emerge. Having the approach that $\mathrm{BD}$ is pure facts and using it "wrongly", for example by backing one goal rather than another, can result in confusion and frustration both within the organization as well as for society at large, causing moral stress [47]. It is therefore crucial to gain a good understanding of the challenges and complexities of implementing BD in an organization in order to do it wisely.

This empirical study indicates that there is a lack of discussion on ethics at the STA. For example, the STA mentions that anonymization of $\mathrm{BD}$ is primarily considered in order to make it safe to share openly. As we have noted previously, there is no way to anonymize BD entirely [32], [34]. Similarly, Günther et al. [10] indicate that privacy and ethical issues are often considered external to organizations. This finding would seem to hold true for some individuals at the STA, as they consider stakeholders, such as car manufacturers that produce the cars, as being responsible for emissions, and argue that the STA only deals with "dead matter". However, the possibilities of BD analyses when large datasets are aggregated mean that it is not possible to predict how and for what purpose open BD will be used. This can be seen in several cases where BD analyses have had a negative societal impact [32], [34]. Any organization that intends to openly share $\mathrm{BD}$ thus ought to be aware of possible consequences or at least bring these to light and discuss them as it is impossible to predict how BD can be used. It is therefore essential that ethical discussions are conducted at each organization 
dealing with $\mathrm{BD}$ so that wise discussions can lead to wise outcomes that benefit many.

Additionally, it is crucial to raise awareness of the difference in power relations between the BD stakeholders [32]. In the case in this study, the organization primarily acts as the BD collector or BD utilizer. In cases where the organization is not the BD utilizer, it is particularly important to understand that the organization does not have control over how the data is used. This is specifically important in governmental organizations in countries like Sweden, where the Public Access to Information and Secrecy Act is fundamental to the organization. As such, it is important to maintain a continuous dialogue on ethics and privacy within the organization, even if data is anonymized.

Furthermore, the literature highlights that organizations have a deterministic view of artificial intelligence and $\mathrm{BD}$ as something that they have no control over [34]. As relying on BD analyses is fraught with dilemmas such as those identified by this empirical study, it is important that organizations experience a feeling of control over their implementation and use of $\mathrm{BD}$, to incite them to also take responsibility for the consequences of relying on $\mathrm{BD}$ for decision making. This study shows that the STA is worried about losing core values if they rely on $\mathrm{BD}$. This does not have to be the case. It is within the organization's control to implement BD wisely, which includes retaining its core values.

Practical wisdom is experience-based and gained from a dynamic process of trial and error [20]. However, erroneous or unethical use of $\mathrm{BD}$ analyses can have severe societal consequences [10], [11]. There is also, so far, limited experience as concerns relying on $\mathrm{BD}$ for predictions. Therefore, it is a risk for organizations to attempt to rely on BD analyses without a critical reflection on what is responsible or wise to do. With the current hyperbole surrounding $\mathrm{BD}$, and the sense of its potential for innovation, it is easy to omit practical wisdom, thinking that it is not based on data and therefore useless. However, gaining, understanding and using experiences in any type of work, and maybe especially concerning digitalization, is important in order to continue to flourish as humans. To balance the hard facts, aka digital data, with the not-knowing will help in making wise decisions concerning BD use. In addition, with the increase of BD implementation and usage, practical wisdom can assist in making sure that the reasonable thing to do is done and that the result benefits the common good. Otherwise, if not dealing with dilemmas such as those presented in this paper, there is a risk of negative consequences for the organization or society. This paper thus aims to shed light on wise implementation of BD.

\section{Conclusion}

This paper set out to understand an organization's attitude towards implementing BD analyses and has demonstrated that, in order to implement BD analyses in the organization wisely, it is necessary to deal with dilemmas in which there may not be a desirable or predictable outcome.

While $\mathrm{BD}$ is perceived as having great potential to support the main goal of organizations, it may negatively affect other goals, and there is a risk that critical questions are neglected within the organization, as the full potential and consequences of using BD have yet to be explored. Nevertheless, it is important to retain control of the organization's core values when wisely implementing BD.

This paper presents dilemmas that are brought to light with the help of a theoretical lens of practical wisdom. We conclude that dilemmas are essential for organizations to understand and take action on when implementing $\mathrm{BD}$; however, they can be difficult to identify and understand. The paper further highlights the importance of practical wisdom when implementing BD and presents a detailed empirical account of an organization's attitude towards the implementation of BD.

\section{References}

[1] N. Dalal and D. J. Pauleen, "The wisdom nexus: Guiding information systems research, practice, and education", Inf. Syst. J., vol. 29, February 2018, pp. 224-244, Jan. 2019.

[2] V. Eubanks, Automating inequality: How high-tech tools profile, police, and punish the poor. St. Martin's Press, 2018.

[3] R. Martin and T. Golsby-smith, "Management Is Much More Than a Science", Harv. Bus. Rev., no. SeptemberOctober, pp. 1-18, 2017.

[4] C. Russell and N. Bennett, "Big data and talent management: Using hard data to make the soft stuff easy", Bus. Horiz., vol. 58, no. 3, pp. 237-242, 2015.

[5] T. L. Nguyen, “A Framework for Five Big V's of Big Data and Organizational Culture in Firms", in 2018 IEEE Conference on Big Data, 2018, pp. 5411-5413.

[6] M. Ienca and E. Vayena, "On the responsible use of digital data to tackle the COVID-19 pandemic", Nat. Med., vol. 26, no. April, pp. 463-464, 2020.

[7] Y. Zhang, M. Chen, S. Mao, L. Hu, and V. C. M. Leung, "CAP: community activity prediction based on big data analysis", IEEE Netw., no. August, pp. 52-57, 2014.

[8] Y. Lv, Y. Duan, W. Kang, Z. Li, and F. Wang, "Traffic Flow Prediction with Big Data: A Deep Learning Approach", IEEE Trans. Intell. Transp. Syst., vol. 16, no. 2, pp. 865-873, 2015.

[9] C. O'Neil, Weapons of Math Destruction: How big data increases inequality and threatens democracy. Crown, 
2016.

[10] W. A. Günther, M. H. R. Mehrizi, M. Huysman, and F. Feldberg, "Debating big data: A literature review on realizing value from big data", J. Strateg. Inf. Syst., vol. 26, pp. 191-209, 2017.

[11] K. Kappler, J. Felix, S. Lena, and U. Johannes, "Societal Implications of Big Data", KI - Künstliche Intelligenz, vol. 32, no. 1, pp. 55-60, 2018.

[12] T. Hagendorff, "The Ethics of AI Ethics: An Evaluation of Guidelines", Minds Mach., vol. 30, no. 1, pp. 99-120, 2020.

[13] J. Shotter and H. Tsoukas, "Performing phronesis: On the way to engaged judgment", Manag. Learn., vol. 45, no. 4, pp. 377-396, 2014.

[14] J. Shotter and H. Tsoukas, "In Search of phronesis: Leadership and the art of judgment", Acad. Manag. Learn. Educ., vol. 13, no. 2, pp. 224-243, Jun. 2014.

[15] N. Kandasamy et al., "Interoceptive Ability Predicts Survival on a London Trading Floor", Sci. Rep., vol. 6, pp. $1-7,2016$.

[16] A. Intezari and D. J. Pauleen, "Conceptualizing Wise Management Decision-Making: A Grounded Theory Approach", Decis. Sci., vol. 49, no. 2, pp. 335-400, 2018.

[17] P. C. Nascimento Souto, "Ontological not-knowing to contribute attaining practical wisdom: Insights from a notknowing experience in 'samba-de-gafieira' dance to the value of being and responding from within our practical experience and practical knowledge", Learn. Cult. Soc. Interact., vol. 21, no. December 2018, pp. 48-69, Jun. 2019.

[18] U. Schultze, "What kind of world do we want to help make with our theories?", Inf. Organ., vol. 27, no. 1, pp. 60-66, Mar. 2017.

[19] P. Zackariasson, A. Styhre, and T. L. Wilson, "Phronesis and Creativity: Knowledge Work in Video Game Development", Creat. Innov. Manag., vol. 15, no. 4, pp. 419-429, 2006.

[20] C. Rodgers, "Defining reflection: Another look at John Dewey and reflective thinking", Teach. Coll. Rec., vol. 104, no. 4, pp. 842-866, 2002.

[21] J. Liebowitz, Y. Chan, T. Jenkin, and J. Paliszkiewicz, "If numbers could 'feel': How well do executives trust their intuition?", J. Inf. Knowl. Manag. Syst., vol. 49, no. 4, pp. 531-545, 2019.

[22] C. Birmingham, "Phronesis: A model for pedagogical reflection", J. Teach. Educ., vol. 55, no. 4, pp. 313-324, Sep. 2004.

[23] E. Bardone and M. Lind, "Towards a phronetic space for responsible research (and innovation)", Life Sci. Soc. Policy, vol. 12, no. 1, Dec. 2016.

[24] B. Flyvbjerg, "Phronetic planning research: Theoretical and methodological reflections", Plan. Theory Pract., vol. 5, no. 3, pp. 283-306, 2004.

[25] I. Nonaka and R. Toyama, "Strategic management as distributed practical wisdom (phronesis)", Ind. Corp. Chang., vol. 16, no. 3, pp. 371-394, Jun. 2007.

[26] M. Silvia Vaccarezza, "An Eye on Particulars with the End in Sight: An Account of Aristotelian Phronesis", Metaphilosophy, vol. 49, no. 3, pp. 246-261, Apr. 2018.

[27] H. Tsoukas and S. Cummings, "Recovery: Emergence Organization Marginalization”, Organ. Stud., vol. 18, no.
4, pp. 655-683, 1997.

[28] B. P. Russom, "Managing Big Data - TDWI Best Practice Report”, 2013.

[29] R. H. R. R. Harper, "The Role of HCI in the Age of AI", Int. J. Hum. Comput. Interact., vol. 35, no. 15, pp. 13311344, Sep. 2019.

[30] C. M. Olszak and J. Zurada, "Big Data-driven Value Creation for Organizations", in Proceedings of the 52nd Hawaii International Conference on System Sciences, 2019, vol. 6, pp. 164-173.

[31] R. Patgiri and A. Ahmed, "Big Data: The V's of the Game Changer Paradigm", in IEEE Computer Society, 2016.

[32] A. Zwitter, "Big Data ethics", Big Data Soc., vol. 1, no. December, pp. 1-6, 2014.

[33] G. George, M. Haas, and A. Pentland, "From the Editors: Bi Data and Management", Acad. Manag. J., vol. 57, no. 2, pp. 321-326, 2014.

[34] D. Greene, A. L. Hoffmann, and L. Stark, "Better, Nicer, Clearer, Fairer: A Critical Assessment of the Movement for Ethical Artificial Intelligence and Machine Learning", in Proceedings of the 52nd Hawaii International Conference on System Sciences, 2019, pp. 2122-2131.

[35] H. Rittel and M. Webber, "Dilemmas in general theory of planning”, Policy Sci., vol. 4, no. 2, pp. 155-169, 1973.

[36] L. Mathiassen, "Designing Engaged Scholarship: From Real-World Problems to Research Publications", Engag. Manag. Rev., vol. 1, no. 1, 2017.

[38] U. Flick, "Triangulation in Qualitative Research", in $A$ Companion to Qualitative Research, SAGE Publications, 2004, pp. 178-183.

[39] V. Braun and V. Clarke, "Using thematic analysis in psychology", Qual. Res. Psychol., vol. 3, no. 2, pp. 77101, 2006.

[40] J. Saldana, The Coding Manual for Qualitative Researchers, 2nd ed. SAGE Publications, 2013.

[41] G. A. Bowen, "Grounded Theory and Sensitizing Concepts", Int. J. Qual. Methods, vol. 5, no. 3, pp. 12-23, 2006.

[42] J. Van Maanen, J. B. Sørensen, T. R. Mitchell, and T. R. Mitchell, "Introduction to Special Topic Forum: The Interplay between Theory and Method", Acad. Manag. Rev., vol. 32, no. 4, pp. 1145-1154, 2007.

[43] Ö. Kvalnes, Moral Reasoning at Work:Rethinking Ethics in Organizations. 2015.

[44] P. Hayes, I. Van De Poel, M. Steen, and P. Hayes, "Algorithms and values in justice and security", AI Soc., no. $0123456789,2020$.

[45] L. Huang, "When It's OK to Trust Your Gut on a Big Decision", Harv. Bus. Rev., no. October, pp. 3-7, 2019.

[46] J. Crossman and V. Doshi, "When Not Knowing is a Virtue: A Business Ethics Perspective", J. Bus. Ethics, no. May 2014, pp. 1-8, 2015.

[47] S. J. Reynolds, B. P. Owens, and A. L. Rubenstein, "Moral Stress: Considering the Nature and Effects of Managerial Moral Uncertainty", J. Bus. Ethics, vol. 106, no. 4, pp. 491-502, 2012. 